\title{
Genetic Analysis of NROB1 in Congenital Adrenal Hypoplasia Patients: Identification of a Rare Regulatory Variant Resulting in Congenital Adrenal Hypoplasia and Hypogonadal Hypogonadism without Testicular Carcinoma in situ
}

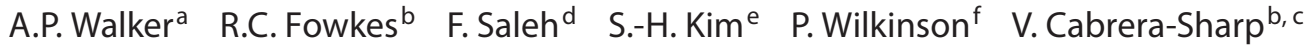 \\ P.J. Talmud ${ }^{a}$ S.E. Humphries ${ }^{a} \quad$ L.H.J. Looijengag P.M.G. Bouloux ${ }^{d}$ \\ ${ }^{a}$ Centre for Cardiovascular Genetics, BHF Laboratories, UCL Institute of Cardiovascular Science, UCL, \\ ${ }^{b}$ Endocrine Signalling Group and ${ }^{C}$ Veterinary Basic Sciences, Royal Veterinary College, University of London, \\ ${ }^{d}$ Centre for Neuroendocrinology, UCL Medical School, Royal Free Campus, e Division of Biomedical Sciences, \\ St. George's Medical School, University of London, and ' Department of Neurology, Royal Free Hospital, London, UK; \\ ${ }^{9}$ Department of Pathology, Erasmus MC-University Medical Center Rotterdam (Daniel den Hoed Cancer Center), \\ Josephine Nefkens Institute, Rotterdam, The Netherlands
}

\section{Key Words}

Carcinoma in situ - Congenital adrenal hypoplasia $\cdot$ DAX1 • Hypogonadotropic hypogonadism $\cdot N R O B 1 \cdot \mathrm{OCT} 3 / 4 \cdot$ Testis

\begin{abstract}
There have been few testicular histology reports of adult patients with congenital adrenal hypoplasia/hypogonadal hypogonadism $(\mathrm{AHC} / \mathrm{HH})$, but Leydig cell hyperplasia has been observed, an indicator of the possibility of malignant transformation. We aimed to define the basis of $\mathrm{AHC} / \mathrm{HH}$ in 4 pedigrees of different ethnic backgrounds. One patient was elected to have testicular biopsy which was examined for evidence of carcinoma in situ (CIS). NROB1 mutation analysis was performed by sequence analysis. NROB1 expression was investigated by RT-PCR. Testicular biopsy sections were stained with HE or immunostained for OCT3/4, an established marker of CIS. We identified NROB1 variants in the 4 AHC pedigrees: pedigree 1 (United Arab Emirates), c.1130A $>$ G predicting p.(Glu377Gly); pedigree 2 (English Caucasian), c.327C >A predicting p.(Cys109*); pedigree 3 (Oman), a 6-bp
\end{abstract}

\section{KARGER}

Fax +4161306 1234

E-Mail karger@karger.ch

www.karger.com (c) 2012 S. Karger AG, Basel

1661-5425/12/0066-0284\$38.00/0

Accessible online at:

www.karger.com/sxd deletion of a direct repeat, c.857_862delTGGTGC predicting p.(Leu286_Val287del); pedigree 4 (English Caucasian), c.1168+1G $>A$, a regulatory variant within the $N R O B 1$ splice donor site. This last male patient, aged 30 years, presented with evidence of $\mathrm{HH}$ but incomplete gonadotrophin deficiency, following an earlier diagnosis of Addison's disease at 3 years. Hormonal therapy induced virilisation. Testicular biopsy was performed. The c.1168+1G >A variant abrogated normal splicing of testicular mRNA. Histological examination showed poorly organised testicular architecture and absence of spermatozoa. Morphological analyses and the absence of immunohistochemical staining for OCT3/4 excluded the presence of malignant germ cell cancer and its precursor lesion, $\mathrm{CIS}$. These studies add to the knowledge of the types and ethnic diversity of $N R O B 1$ mutations and their associated phenotypes, and provide insight into the assessment and interpretation of testicular histology in AHC and $\mathrm{HH}$.

Copyright $\odot 2012$ S. Karger AG, Basel

A.P.W. and R.C.F. contributed equally to this work.
Dr. Ann Walker

Centre for Cardiovascular Genetics, BHF Laboratories

UCL Institute of Cardiovascular Science

5 University Street, London WC1E 6JJ (UK)

Tel. +44 207679 6279, E-Mail ann.walker@ucl.ac.uk 
The atypical orphan nuclear receptor NR0B1 (OMIM 300473, previously called DAX1, dosage-sensitive sexreversal adrenal hypoplasia critical region on the Xchromosome protein 1) is a critical regulator of adrenal and gonadal development, where it is the major negative regulator of steroidogenic factor-1 (NR5A1) [Zanaria et al., 1994; Phelan and McCabe, 2001; Achermann, 2005]. The NROB1 gene was identified by a positional cloning strategy which mapped partially overlapping deletions associated with a contiguous gene deletion syndrome involving congenital adrenal hypoplasia (AHC), hypogonadal hypogonadism $(\mathrm{HH})$, Duchenne muscular dystrophy and glycerol kinase deficiency [Monaco et al., 1992; Walker et al., 1992]. Point mutation of NROB1 was demonstrated to cause both phenotypes of AHC and $\mathrm{HH}$ (OMIM 300200), highlighting its importance in the development and function of the adrenal gland and testis [Muscatelli et al., 1994]. Expression of missense variants in vitro resulted in translation of non-functional or functionally impaired NR0B1 protein [Brown et al., 2003]. Only 3 regulatory variants have been reported and the molecular consequences of NROB1 mutation upon testis mRNA levels have not been investigated previously.

The phenotypic spectrum of patients with NROB1 sequence variants is broad, but usually involves adrenal insufficiency presenting either neonatally or during infancy and $\mathrm{HH}$ in adulthood. However, normal puberty has been reported and even instances of precocious puberty. In adult male patients with $\mathrm{AHC}$ and $\mathrm{HH}$ due to $\mathrm{NROB1}$ mutation, histological analyses of testicular biopsies have shown Leydig cell hyperplasia, indicating the possibility of malignant transformation [Seminara et al., 1999; Ozisik et al., 2003]. Male patients with a range of reproductive disorders collectively termed testicular dysgenesis syndrome are screened for the presence of the precursor of malignant germ cell tumour, carcinoma in situ (CIS) [Sonne et al., 2008]. This typically involves testicular histology and immunostaining for the transcription factor OCT3/4 (encoded by POU5F1), which is an established marker of CIS [Looijenga et al., 2003; de Jong et al., 2005]. In the mouse, NR0B1 also plays a role in maintenance of the pluripotency of embryonic stem cells. Interestingly, this is mediated via transcriptional regulation of POU5F1, the mouse orthologue of human OCT3/4, which is a marker of CIS [Kelly et al., 2010; Jadhav et al., 2011]. In patients with $\mathrm{AHC}$ and $\mathrm{HH}$ due to mutation of NROB1, testicular OCT3/4 investigation has not been reported previously.

Genetic Analysis of NROB1 in Congenital

Adrenal Hypoplasia Patients

\section{Patients and Methods}

\section{Patients}

Pedigree 1 originated from the United Arab Emirates. Seven males in this consanguineous family had been diagnosed with AHC; 2 had died in infancy (fig. 1). The oldest affected patient (1III:15) did not attain puberty and was diagnosed with $\mathrm{HH}$; puberty was induced by testosterone therapy. He died in a road traffic accident aged 16 years. NROB1 sequence was investigated for 2 cousins diagnosed with AHC (1-IV:6 and 1-IV:4, 5 and 3 years, respectively).

Pedigree 2 was of English origin; 3 males were affected with AHC and $\mathrm{HH}$ (fig. 2). NROB1 sequence was investigated for the cousins 2-III:1 and 2-III:5.

Pedigree 3 was of Omani origin. Eleven males had either died neonatally or in infancy, or had been diagnosed with AHC and treated (fig. 3). NROB1 sequence was investigated for 3 brothers (3-III:14, 3-III:17 and 3-III:18) and their mother (3-II:11).

Pedigree 4 was of English origin. A single male case (4-II:1) was identified. He was an only child and had no family history of AHC or HH. He had been diagnosed with Addison's disease aged 3 years. He had not spontaneously entered puberty by 30 years of age and presented with evidence of $\mathrm{HH}$, although he did not have a complete deficiency of FSH.

During childhood, adolescence and early adulthood, patient 4-II:1 was stabilised on hydrocortisone, fludrocortisone and latterly on hydrocortisone (15 mg morning, $10 \mathrm{mg}$ evening), with fludrocortisone $0.5 \mathrm{mg}$ twice daily. On examination aged 30 years, he had a high-pitched voice and no facial, axillary or limb hair. His testes were small, 2 and $3 \mathrm{ml}$, with scant pubic hair; his penis was Tanner stage 2 (11). Luteinizing hormone (LH) was 0.5 IU/l (reference range: 1.7-8.6), follicle-stimulating hormone (FSH) 4.5 IU/l (1.5-12.4), oestradiol <70 pmol/l (28-156), testosterone $0.8 \mathrm{nmol} / \mathrm{l}(6.7-26.0)$, sex hormone-binding globulin (SHBG) $54 \mathrm{nmol} / \mathrm{l}$ (14-49), thyroid stimulating hormone (TSH) $3.0 \mathrm{mU} / \mathrm{l}(0.30-4.20)$ and free thyroxine $14.8 \mathrm{pmol} / \mathrm{l}(12.0-22.0)$. Human chorionic gonadotropin (HCG) treatment was started $(2,000 \mathrm{U}$ twice weekly, IM). Within 2 years, testes had increased to $4 \mathrm{ml}$ (testosterone $17.9 \mathrm{nmol} / \mathrm{l}$, LH $0.4 \mathrm{IU} / \mathrm{l}$ and FSH $3.4 \mathrm{IU} / \mathrm{l}$ ). Within 4 years testicular volume was $\sim 8 \mathrm{ml}$, of softish consistency, with penis stage $4 / 5$, axillary hair stage $2-3$ and pubic hair stage 4 . His voice had broken and there was increased musculature. The patient opted for testosterone implants, receiving 800 mg every 6 months. Within 4 months, testosterone was 14.0 $\mathrm{nmol} / \mathrm{l}, \mathrm{LH}<0.3 \mathrm{IU} / \mathrm{l}, \mathrm{FSH} 3.0 \mathrm{IU} / \mathrm{l}$ and oestradiol $<70 \mathrm{pmol} / \mathrm{l}$. He remained on testosterone implants, becoming fully virilised. The patient elected to have a testicular biopsy to exclude premalignant changes. During this time, his bone density gave an L1-L4 T-score of -3.67 (bone mineral density, BMD 0.688) and -2.26 in the right hip (BMD 0.778), indicative of established osteoporosis (biochemistry, on testosterone replacement: LH 0.1 IU/l, FSH 0.4 IU/l, testosterone $16.6 \mathrm{nmol} / \mathrm{l}$, SHBG $31.3 \mathrm{nmol} / \mathrm{l}$ ).

\section{Methods}

For mutation analysis, the NROB1 gene was PCR-amplified from genomic DNA for automated sequence analysis [Muscatelli et al., 1994]. NROB1 sequence was compared to Transcript refseq ID NM_000475.4; the intron sequence is contained in Genomic refseq ID NG_009814.1 on chromosome X. Total RNA was purified from snap-frozen testicular biopsy samples from the patient 


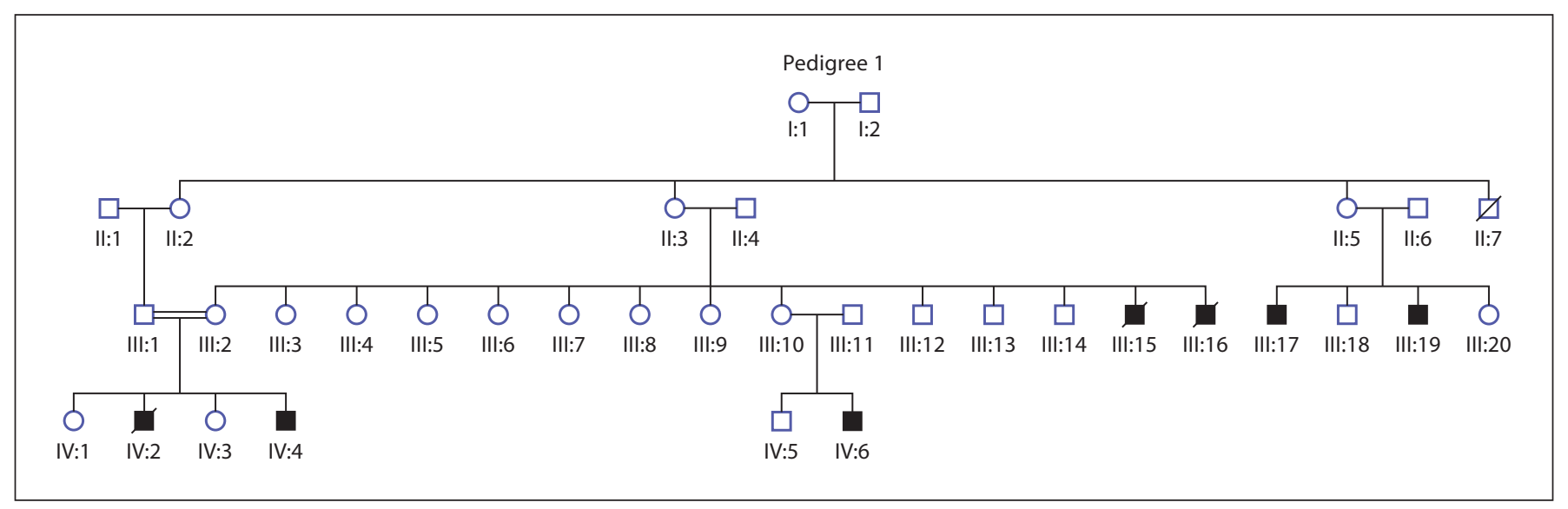

Fig. 1. Pedigree 1 (United Arab Emirates).

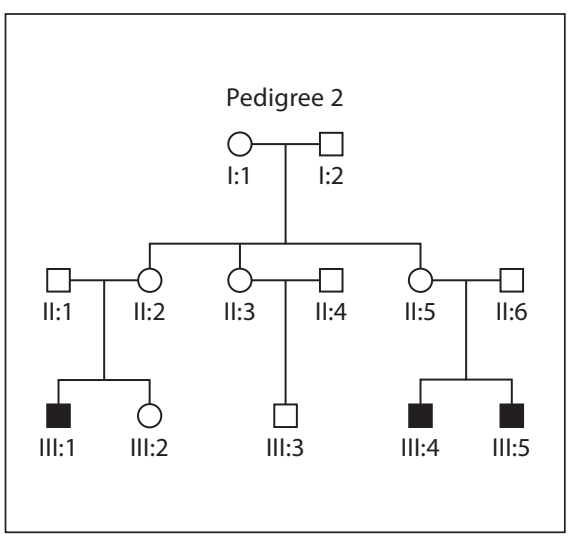

Fig. 2. Pedigree 2 (English Caucasian).

and a control individual without symptoms of AHC (RNeasy Mini Kit, Qiagen, UK). cDNA was synthesised and amplified using a touchdown PCR protocol to examine expression of NROB1 and $A C T B$. The NROB1 primers used were RTEX1BF-NEW (GCTTTCTTTCCAAATGCTG) and RTEX2R-NEW (ATGATGGGCCTGAAGAACAG) for amplification of the predicted 271bp product. The RT-PCR was performed twice using 2 independent RNA preparations from separate portions of the testicular biopsy.

For immunohistochemistry, $3-\mu \mathrm{m}$ sections were cut from the prepared testis biopsy block. Parallel sections were stained with hematoxylin and eosin (H\&E) or immunostained for OCT3/4 (an established marker of CIS) [Looijenga et al., 2003; de Jong et al., 2005], using a mouse monoclonal antibody directed against amino acids 1-134 of human OCT3/4 (SC-5279, Santa Cruz, Heidelberg, Germany; 1:350 dilution). The sections were evaluated by a pathologist experienced in germ cell tumour pathology (J.W. Oosterhuis, Erasmus MC Rotterdam, The Netherlands) [Ooster- huis and Looijenga, 2005; van Casteren et al., 2008]. Evidence of CIS was assessed on both H\&E and OCT3/4 staining. CIS was morphologically defined as the presence of large, atypical intratubular cells with large hyperchromatic nuclei containing several prominent nucleoli [Oosterhuis and Looijenga, 2005; van Casteren et al., 2008].

\section{Results}

In pedigree 1 , sequence analysis for the 2 cousins (1-IV:6 and 1-IV:4) identified the presence of a novel missense variant in exon $1, c .1130 A>G$, predicting p.(Glu377Gly). A different missense mutation predicted to affect the same amino acid residue has been reported in AHC patients: c.1129G $>$ A, predicting p.(Glu377Lys) [Zhang et al., 1998; Achermann et al., 2001]. The residue corresponding to E377 is conserved in 3 related nuclear receptors, and modelling implicated a salt bridge between E377 with R425, a residue which has also been identified as affected by sequence variation in AHC: p.(R425G) [Zhang et al., 1998].

In pedigree 2, the c.327C $>\mathrm{A}$ nonsense variant p.(Cys109*) was detected in the 2 cousins tested (2-III:1 and 2-III:5); this variant has been identified previously in a patient with AHC [Phelan and McCabe, 2001].

In pedigree 3, the 3 brothers tested (3-III:14, 3-III:17 and 3-III:18) were found to have a novel deletion of $6 \mathrm{nu}-$ cleotides located within a short direct repeat sequence in exon 1, c.857_862delTGGTGC, predicting p.(Leu286_ Val287del) in the nuclear receptor-like domain; this variant was heterozygous in their mother. A missense variant of residue 287 , c. $860 \mathrm{~T}>\mathrm{G}$, predicting p.(Val287Gly), has 


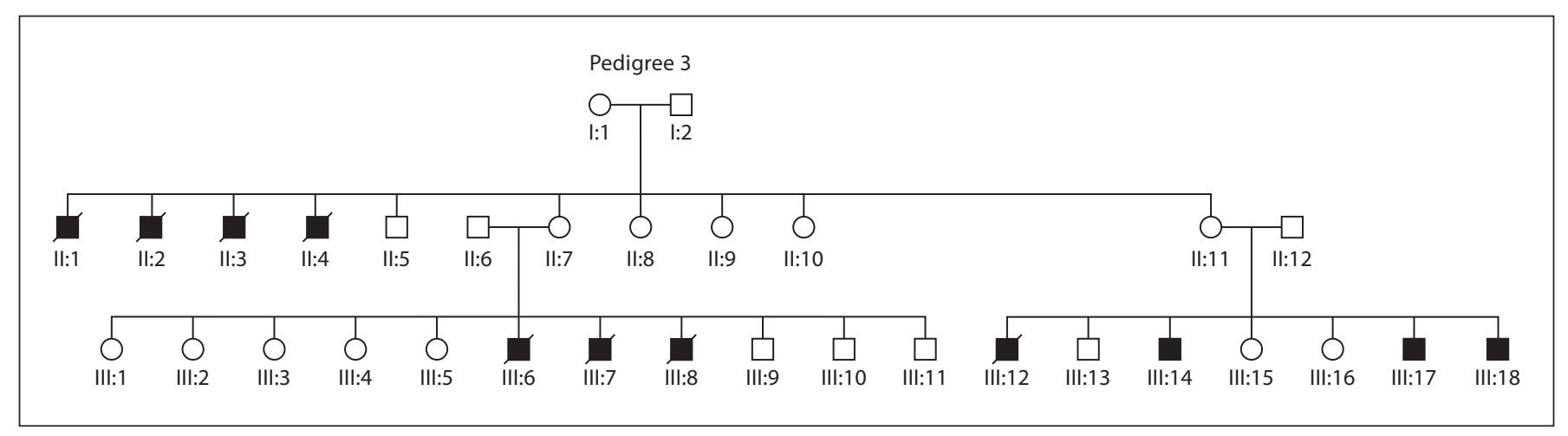

Fig. 3. Pedigree 3 (Oman).

been previously reported to result in $\mathrm{AHC}$ and $\mathrm{HH}$, with additional features of inappropriately tall stature and renal ectopy, features not previously described in AHC [Franzese et al., 2005]. These rare features were not present in the 3 brothers with p.(Leu286_Val287del) described in this report.

In pedigree 4 , DNA sequence analysis revealed a novel variant within the NROB1 splice donor site for patient 4-II:1 (c.1168+1G>A; fig. 4A). Both the location of this variant within the conserved $2 \mathrm{bp}$ of the splice site consensus sequence and its rarity, evidenced by its absence from the 1000 Genomes database (http:// browser.1000genomes.org/index.html), indicated a likely functional variant [The 1000 Genomes Project Consortium, 2010]. Testicular RNA was prepared from the biopsy sample and reverse transcribed for PCR analysis of NROB1 expression using primers located in exons 1 and 2. A product of $271 \mathrm{bp}$ was amplified from the control, but no NROB1 product could be amplified from the patient's testicular RNA, despite amplification of $\beta$-actin $(A C T B)$ as an internal positive control for RNA integrity, indicating absence of the cognate NROB1 mRNA transcript (fig. 4B).

Histological analyses of the testis biopsy showed some sclerotic seminiferous tubules and other tubules beside Sertoli cells only (fig. 5A-D). Spermatocytic differentiation was noted in some tubules, but there were no spermatozoa. Leydig cell numbers appeared substantially decreased. Some areas showed testicular parenchyma containing a mixture of narrow, immature seminiferous tubules and totally fibrosed tubules. The immature tubules contained germ cells at the following stages: spermatogonia, spermatocytes, and very rare, round spermatids. The interstitial space appeared increased due to ede-

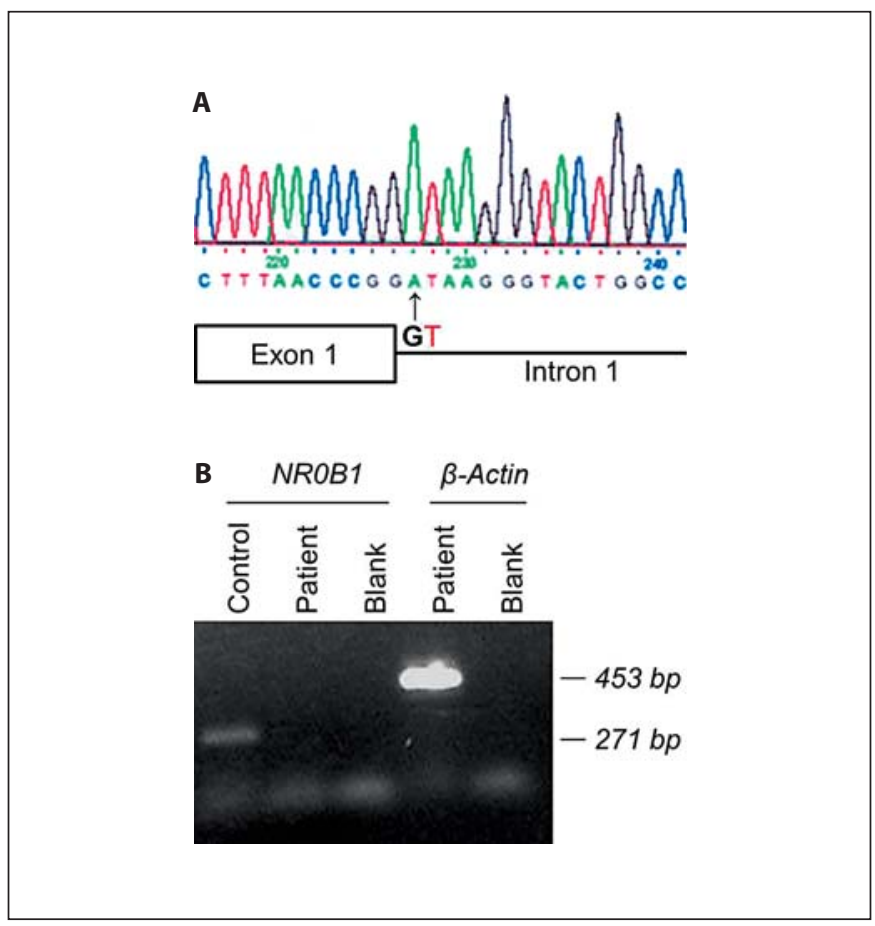

Fig. 4. A Sequence chromatogram showing mutation of the NROB1 splice donor site (c.1168+1G>A) in patient 4-II:1. NR0B1 sequence was compared to Transcript refseq ID NM_000475.4; the intron sequence is contained in Genomic refseq ID NG_009814.1 on chromosome X. B RT-PCR analysis of RNA extracted from control testis gave the 271-bp cognate NROB1 band. This could not be amplified from 2 independent RNA preparations from portions of the testicular biopsy of patient 4-II:1. Amplification of the $\beta$ actin gene (453 bp) confirmed mRNA integrity. 
Fig. 5. Testicular biopsy tissue stained with HE (A-D), or for OCT3/4 (E, F), shows features consistent with an immature testis, but no evidence of CIS. A-D Sertoli cells were detected, but very few Leydig cells were seen. Many examples of fibrotic tubules were observed. No spermatozoa were present in the lumen of the seminiferous tubules. $\mathrm{F}=$ Area of fibrosis; $\mathrm{IT}=$ areas showing immature tubuli; $\mathrm{LC}=$ increased interstitial areas containing reduced numbers of Leydig cells; SC = Sertoli cells; ST = sclerotic tubuli. E OCT3/4 expression (as a marker of CIS) in biopsy tissue was negative in the patient. F Positive control; OCT3/4 expression in a confirmed CIS patient, showing brown staining in the transformed germ cells. The scale bar indicates $100 \mu \mathrm{m}$. The objective magnification is indicated for each panel; the ocular magnification was $10 \times$ for all panels.
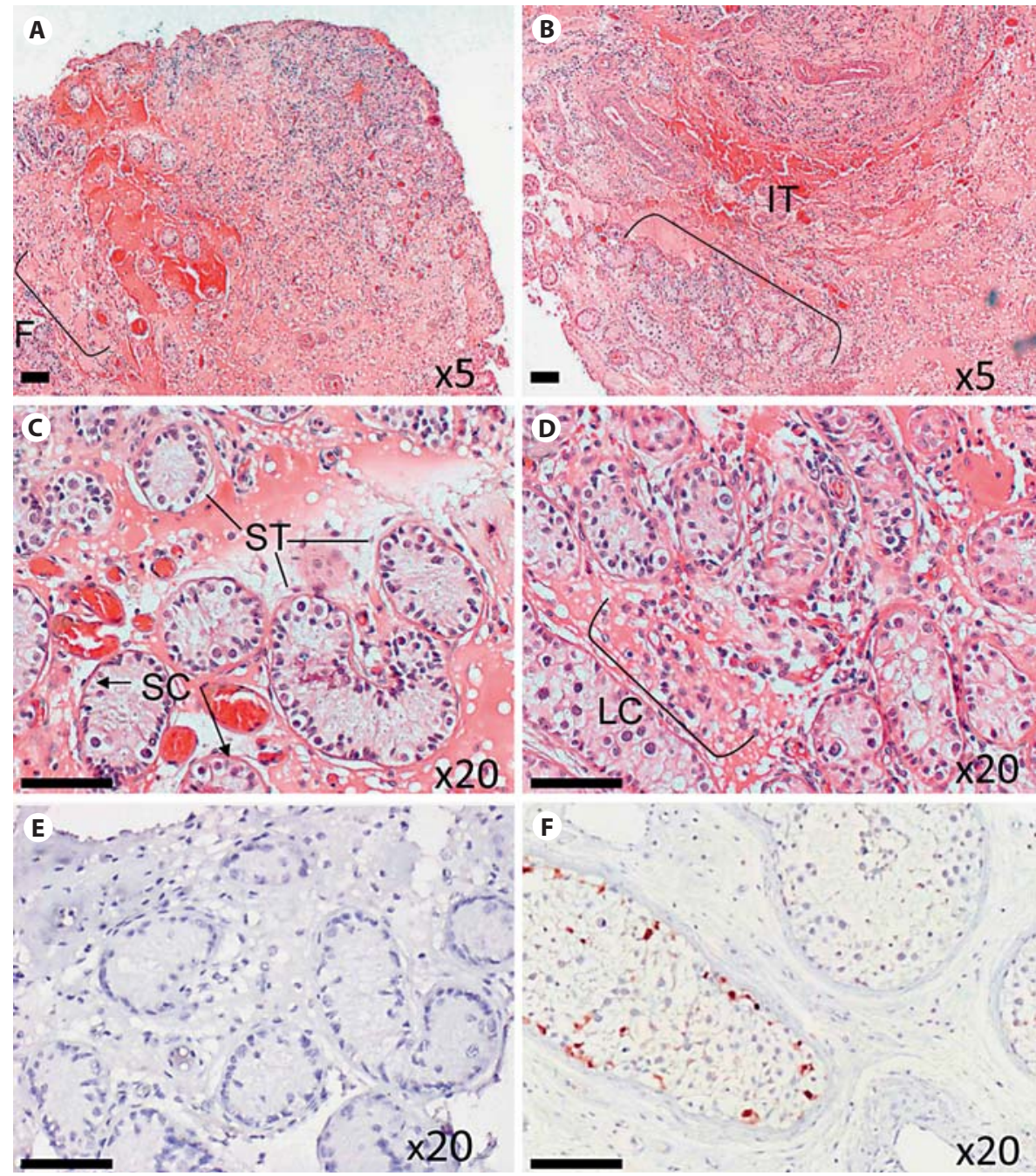

ma, fibrosis and a dense lymphocytic infiltrate. However, there was no morphological evidence of CIS or an invasive germ cell tumour; this was confirmed by the absence of staining for OCT3/4 in the patient biopsy (fig. 5E), as compared to the positive control section (fig. $5 \mathrm{~F}$ ).

\section{Discussion}

We report 4 NROB1 mutations, 3 of which are novel and 1 is a rare regulatory variant, demonstrating the first NROB1 mutations in patients of Arabic origin. We provide the first investigation of CIS in testicular biopsy tissue from a patient with $\mathrm{AHC}$ and $\mathrm{HH}$ due to NROB1 mutation, demonstrating it to be absent in this case. In general, male patients with testicular dysgenesis syndrome are screened for CIS; OCT3/4, an established marker of CIS, is negatively regulated by NR0B1. When testicular biopsy is indicated for $\mathrm{HH}$ caused by mutation of NROB1, CIS should be investigated both morphologically (HE) and specifically by OCT3/4 staining. These data will provide evidence of the risk of CIS and allow guidelines to be established for screening of CIS in NROB1-related AHC with $\mathrm{HH}$.

Testicular histology associated with NROB1 sequence variants has previously been described in only 2 prepubertal cases and 3 adults. A neonate who died due to AHC, the sibling of a patient with the c.1197C $>$ A variant, predicting p.(Y399*), had normal testicular architecture [Brown et al., 2003]. A 9-year-old boy with AHC and undescended, prepubertal testes had the c.1355delT variant; this predicts a frameshift with the first premature termi- 


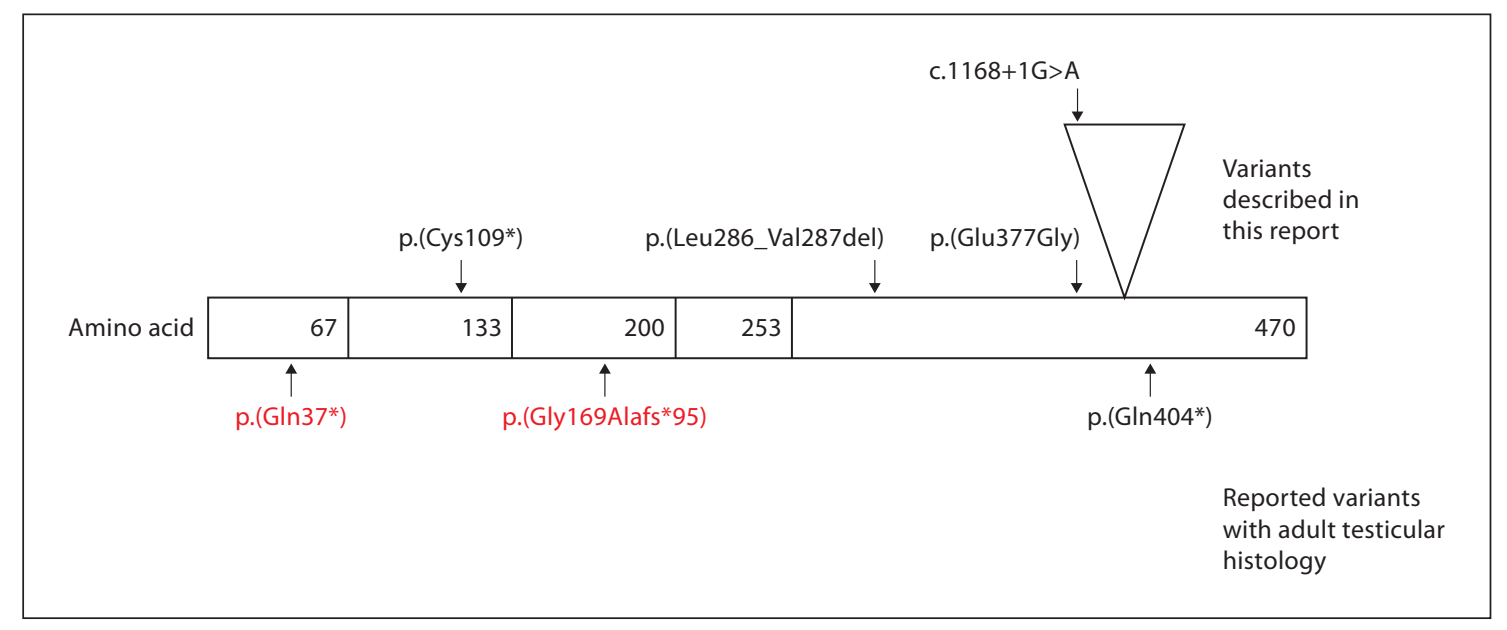

Fig. 6. Schematic representation of the NR0B1 predicted protein. The $\mathrm{N}$-terminal portion of the predicted nuclear receptor protein encodes 3 and a half repeat domains and the $\mathrm{C}$-terminal encodes the nuclear receptor-like domain. Variants described in this report are shown above the protein schematic image, and the 3 previously reported variants for which adult testicular histology has been described are shown below. The position of the single intron is indicated as an upturned triangle, indicating the intronic position of the c.1168+1G $>$ A splice variant. Variants for which adult testicular histology showed Leydig cell hyperplasia are shown in red. nation at codon 461, p.(Ile452Thrfs*10). This infant also had normal testicular architecture [Morii et al., 2007]. An adult with mild phenotype (adult-onset adrenal insufficiency and gonadal failure) had an amino-terminal NR0B1 nonsense variant, c.109C $>$ T, predicting p.(Gln37*) (fig. 6). In vitro studies showed expression of amino-truncated, partially functional protein from an alternative, in-frame initiation site (M83), deduced to reduce clinical severity. He had been treated with gonadotrophins for 6 months. His testicular biopsy showed disorganized seminiferous tubular structures and moderate Leydig cell hyperplasia [Ozisik et al., 2003]. Another adult patient with $\mathrm{AHC}$ and $\mathrm{HH}$ and the c.501delA variant predicting p.(Gly169Alafs*95) had a testicular biopsy after 7 years of HCG treatment; Sertoli cell only syndrome was reported, with infrequent spermatogonia, no evidence of spermatogenesis, and Leydig cell hyperplasia (fig. 6) [Seminara et al., 1999]. Recently, an adult with $\mathrm{AHC}$ and $\mathrm{HH}$ and the NROB1 c. $1210 \mathrm{C}>\mathrm{T}$ variant, predicting p.(Gln404*) (fig. 6), had 20 months treatment with menotropin and HCG; bilateral multiple-site testicular biopsy was performed. Although histology showed very severe reduction in spermatogenesis, a few spermatozoa were extracted for intracytoplasmic sperm injection and embryo transfer, leading to birth of a healthy boy. Thus, there are very few data on testicular function, but they suggest that patients with NR0B1 variants ap- pear to have a primary defect of the testes which is progressive with increasing age, in addition to testicular defects secondary to central $\mathrm{HH}$ [Frapsauce et al., 2011]. We report histological analyses of the adult patient 4-II:1 which confirm an extremely compromised testicular architecture, failure of spermatogenesis at a cellular level with absence of spermatozoa. As our recent evidence suggests that histological examination alone can be insufficient to exclude CIS [van Casteren et al., 2008], we also performed OCT3/4 immunostaining, showing no detectable expression in the biopsy sample. There was neither evidence of malignant germ cell tumour, nor of its precursor lesion, CIS. Although sampling error must always be considered for analysis of single site biopsies, based upon our previous studies of CIS, there is no evidence to suggest that the patient is at future risk for development of a malignant germ cell tumour, either a seminoma or nonseminoma [Looijenga et al., 2003; de Jong et al., 2005; Oosterhuis and Looijenga, 2005; van Casteren et al., 2008].

Few variants of regulatory sequences have been reported for NROB1. Two different NROB1 splice site variants have been identified in boys with $\mathrm{AHC}$ and $\mathrm{HH}, \mathrm{c} .1169-1 \mathrm{G}>\mathrm{C}$ and c.1168+1G $>\mathrm{C}$ [Goto and Katsumata, 2009; Landau et al., 2010]. Over-expression of c.1168+1G $>$ C in COS-1 (monkey kidney) cells and RTPCR showed multiple alternatively spliced transcripts, 
including a band the same size as the cognate NROB1 product [Goto and Katsumata, 2009], possibly reflecting non-physiological NROB1 transcriptional regulation under heterologous over-expression. In comparison, in our current study of the novel c.1168+1G $>$ A variant, no cognate NROB1 transcript was RT-PCR amplified from the patient's testicular RNA, predicting physiological absence of NR0B1 protein. Lack of sample precluded further analysis of the testicular RNA, so we cannot exclude the possibility that alternative splicing across the region encompassed by the primers, corresponding to amino acids 363-453 in the nuclear receptor-like domain, may have resulted in some level of expression of a transcript encoding a partially functional protein. The only other regulatory variant of $\mathrm{NROB1}$ described in a patient with $\mathrm{AHC}$ and $\mathrm{HH}$ was a $60-\mathrm{Mb}$ inversion with 1 breakpoint in a non-coding, conserved element $\sim 4 \mathrm{~kb}$ upstream of NROB1 [Skinningsrud et al., 2009]. The c.1168+1G $>$ A variant described in patient 4-II:1 in this report, together with the 2 previous splice site variants and the inversion, are the only reported $N R O B 1$ variants affecting non-coding, regulatory sequences.

In summary, we have identified NROB1 sequence variants in $4 \mathrm{AHC} / \mathrm{HH}$ pedigrees. Three are novel, and 2 represent the first NROB1 variants reported in patients of Arabic ethnic origin. The necessity for clinical suspicion and rapid diagnosis of AHC to avoid familial instances of multiple male neonatal or infant deaths is illustrated by pedigrees 1 and 3 (fig. 1, 3). We have described in patient 4-II:1 a novel splice donor site variant in NROB1 that abrogated cognate splicing of testicular mRNA. Patient 4-II:1 had clinical features consistent with an incomplete FSH deficiency with some retention of hypothalamic-pituitary signalling, insufficient to spontaneously induce/ maintain puberty, but consistent with the observed growth of the testes on HCG treatment and the histological evidence of spermatocytic differentiation, although no mature spermatozoa were observed. For patient 4-II:1 with the c.1168+1G>A variant, testicular biopsy showed neither malignant germ cell tumour, nor its precursor lesion, CIS. These studies add to knowledge of the types and ethnic diversity of NROB1 sequence variants and their associated phenotypes, and provide insight into the assessment and interpretation of testicular histology in $\mathrm{AHC}$ and $\mathrm{HH}$.

\section{Acknowledgements}

We thank the patients, their families, and the clinical staff for their participation, Inessa Carrick for administrative assistance and Judith Kisalu for clinical data.

\section{References}

Achermann JC: The role of SF1/DAX1 in adrenal and reproductive function. Ann Endocrinol 66:233-239 (2005).

Achermann JC, Ito M, Silverman BL, Habiby RL, Pang S, et al: Missense mutations cluster within the carboxyl-terminal region of DAX-1 and impair transcriptional repression. J Clin Endocrinol Metab 86:3171-3175 (2001).

Brown P, Scobie GA, Townsend J, Bayne RA, Seckl JR, et al: Identification of a novel missense mutation that is as damaging to DAX-1 repressor function as a nonsense mutation. J Clin Endocrinol Metab 88:1341-1349 (2003).

de Jong J, Stoop H, Dohle GR, Bangma CH, Kliffen M, et al: Diagnostic value of OCT3/4 for pre-invasive and invasive testicular germ cell tumours. J Pathol 206:242-249 (2005).

Franzese A, Brunetti-Pierri N, Spagnuolo MI, Spadaro R, Giugliano M, et al: Inappropriate tall stature and renal ectopy in a male patient with X-linked congenital adrenal hypoplasia due to a novel missense mutation in the $D A X$ 1 gene. Am J Med Genet A 135:72-74 (2005).
Frapsauce C, Ravel C, Legendre M, Sibony M, Mandelbaum J, et al: Birth after TESE-ICSI in a man with hypogonadotropic hypogonadism and congenital adrenal hypoplasia linked to a DAX-1 (NROB1) mutation. Hum Reprod 26:724-728 (2011).

Goto M, Katsumata N: X-linked adrenal hypoplasia congenita caused by a novel intronic mutation of the DAX-1 gene. Horm Res 71: 120-124 (2009).

Jadhav U, Harris RM, Jameson JL: Hypogonadotropic hypogonadism in subjects with DAX1 mutations. Mol Cell Endocrinol 346:65-73 (2011).

Kelly VR, Xu B, Kuick R, Koenig RJ, Hammer GD: Dax1 up-regulates Oct4 expression in mouse embryonic stem cells via LRH-1 and SRA. Mol Endocrinol 24:2281-2291 (2010).

Landau Z, Hanukoglu A, Sack J, Goldstein N, Weintrob N, et al: Clinical and genetic heterogeneity of congenital adrenal hypoplasia due to NROB1 gene mutations. Clin Endocrinol 72:448-454 (2010).
Looijenga LH, Stoop H, de Leeuw HP, de Gouveia Brazao CA, Gillis AJ, et al: POU5F1 (OCT3/4) identifies cells with pluripotent potential in human germ cell tumors. Cancer Res 63:2244-2250 (2003).

Monaco AP, Walker AP, Millwood I, Larin Z, Lehrach $\mathrm{H}$ : A yeast artificial chromosome contig containing the complete Duchenne muscular dystrophy gene. Genomics 12: 465-473 (1992).

Morii M, Takahashi T, Takahashi I, Komatsu K, Sagishima M, et al: X-linked adrenal hypoplasia congenita: testicular histology before puberty. Pediatr Int 49:526-529 (2007).

Muscatelli F, Strom TM, Walker AP, Zanaria E, Recan D, et al: Mutations in the $D A X-1$ gene give rise to both $\mathrm{X}$-linked adrenal hypoplasia congenita and hypogonadotropic hypogonadism. Nature 372:672-676 (1994).

Oosterhuis JW, Looijenga LH: Testicular germcell tumours in a broader perspective. Nat Rev Cancer 5:210-222 (2005). 
Ozisik G, Mantovani G, Achermann JC, Persani L, Spada A, et al: An alternate translation initiation site circumvents an amino-terminal DAX1 nonsense mutation leading to a mild form of X-linked adrenal hypoplasia congenita. J Clin Endocrinol Metab 88:417-423 (2003).

Phelan JK, McCabe ER: Mutations in NROB1 (DAX1) and NR5A1 (SF1) responsible for adrenal hypoplasia congenita. Hum Mutat 18: 472-487 (2001).

Seminara SB, Achermann JC, Genel M, Jameson JL, Crowley WF Jr: X-linked adrenal hypoplasia congenita: a mutation in DAX1 expands the phenotypic spectrum in males and females. J Clin Endocrinol Metab 84:45014509 (1999).
Skinningsrud B, Husebye ES, Gilfillan GD, Frengen E, Erichsen A, et al: X-linked congenital adrenal hypoplasia with hypogonadotropic hypogonadism caused by an inversion disrupting a conserved noncoding element upstream of the NROB1 (DAX1) gene. J Clin Endocrinol Metab 94:4086-4093 (2009).

Sonne SB, Kristensen DM, Novotny GW, Olesen IA, Nielsen JE, et al: Testicular dysgenesis syndrome and the origin of carcinoma in situ testis. Int J Androl 31:275-287 (2008).

The 1000 Genomes Project Consortium: A map of human genome variation from population-scale sequencing. Nature 467:10611073 (2010).

van Casteren NJ, Stoop H, Dohle GR, de Wit R, Oosterhuis JW, Looijenga LH: Noninvasive detection of testicular carcinoma in situ in semen using OCT3/4. Eur Urol 54:153-158 (2008).
Walker AP, Chelly J, Love DR, Brush YI, Recan $\mathrm{D}$, et al: A YAC contig in Xp21 containing the adrenal hypoplasia congenita and glycerol kinase deficiency genes. Hum Mol Genet 1: 579-585 (1992).

Zanaria E, Muscatelli F, Bardoni B, Strom TM, Guioli S, et al: An unusual member of the nuclear hormone receptor superfamily responsible for X-linked adrenal hypoplasia congenita. Nature 372:635-641 (1994).

Zhang YH, Guo W, Wagner RL, Huang BL, McCabe L, et al: DAX1 mutations map to putative structural domains in a deduced threedimensional model. Am J Hum Genet 62: 855-864 (1998). 